\title{
Design and modelling of novel evacuated receiver tube of concentration solar power system by using heliostat stadium arrangement
}

\author{
Ayad Kadhim Khlief ${ }^{1,2}$, Syed Ihtsham- ul-Haq Gilani ${ }^{1, *}$, Hussain H. Al-Kayiem ${ }^{l}$ and \\ Sanan T. Mohammad ${ }^{I}$ \\ ${ }^{1}$ Department of Mechanical Engineering, Universiti Teknologi PETRONAS, 32610 Bandar Seri \\ Iskandar, Perak, Malaysia. \\ ${ }^{2}$ Department of Electromechanical Engineering, University of Technology, Baghdad, Iraq
}

\begin{abstract}
A novel concentration solar evacuated receiver tube collector is proposed in this study. Details of design and simulation of the heliostat field are presented. The proposed system uses a heliostat stadium arrangement to focus sunlight towards a receiver (evacuated receiver tube). Heliostat field which looks like stadium arrangement is proposed an alternative system of the tower in the power tower plants to cancel the shading / blocking losses. In this study, simulation results showed that the energy input increases with increased solar irradiation; the increase ranges from 288 to $470 \mathrm{~W} / \mathrm{m}$. The maximum amount of energy inputs that can be obtained in the receiver for the collector is around $470 \mathrm{~W} / \mathrm{m}$ for the maximum solar density of $688 \mathrm{~W} / \mathrm{m}^{2}$. In the solar is $402 \mathrm{~W} / \mathrm{m}^{2}$, and the useful energy of collectors is about $288 \mathrm{~W} / \mathrm{m}$ and the thermal efficiency of the receiver was around $23 \%$.
\end{abstract}

\section{Introduction}

The receiver of the solar power tower plant absorbs the solar energy and transfers it to the Heat Transfer Fluid (HTF). Some of the incoming radiation is reflected due to the fact that absorbance of receiver is less than one. Surface temperature increases due to radiation absorption, causing loss by thermal emission and convection. On the edges of the receiver, some losses occur by thermal conductivity in the tower structure [1].

There are several ways to describe or model the thermal performance of an open receiver and cavity using molten salt as heat transfer fluid numerically. In a steady state model presented by $\mathrm{Li}$ et al. [2], there was internal flow in the tubes of the cavity receiver. The thermal performance was analysed considering the effects of several factors like surface of the receiver. Their model was experimentally validated. Lata et al. [3] reported that main heat loss was due to reflection and emissions, while quantifying the mechanism of open receiver. The heat transfer to molten salt was also simulated using a dynamic fluid code. They found that differences in the outer diameter of the tube have shown that efficiency improves when diameter is reduced. Yang et al. [4] performed the computational fluid dynamics (CFD) analysis to simulate heat transferred to the flow of molten salt in the tube. Their results were in good matching with experimental ones.

In this work, we report on the design and mathematical model of a novel concentrated evacuated receiver tube solar collector via heliostat stadium. The system is novel in the many regards. The purpose of this model is to understand the operation of the receiver

\footnotetext{
* Corresponding author: syedihtsham@utp.edu.my
} 
when exposed to solar radiation reflected from heliostat field. This paper also tries to find an approach to determine various collector parameters from measurements under non equilibrium conditions.

\section{Design of evacuated tube receiver system}

The main components of the proposed system are the (i) heliostat concentrator and (ii) evacuated tube receiver Figure 1. Evacuated tube absorbs which receives concentrated light from the heliostat and serves as the high-temperature fluid. An evacuated tube receiver comprising 4 tubes with aperture area $0.8 \mathrm{~m}^{2}$ were installed on a steel structure. The receiver was installed on a North facing base. Initial investigations of the heliostat field led to a determination of 12 heliostats to be utilized in simulating the facility. The reflectivity established for the heliostat is $89 \%$. Heliostats of collective reflective surface area $37.5 \mathrm{~m}^{2}$ were selected for modeling of the facility, distributed as shown in Fig. 1, the distance between the tower and first row of heliostats is 10 meters, where as, the inter-row distance is $3.5 \mathrm{~m}$. The reflection area of each mirror is $3.75 \mathrm{~m}^{2}$.

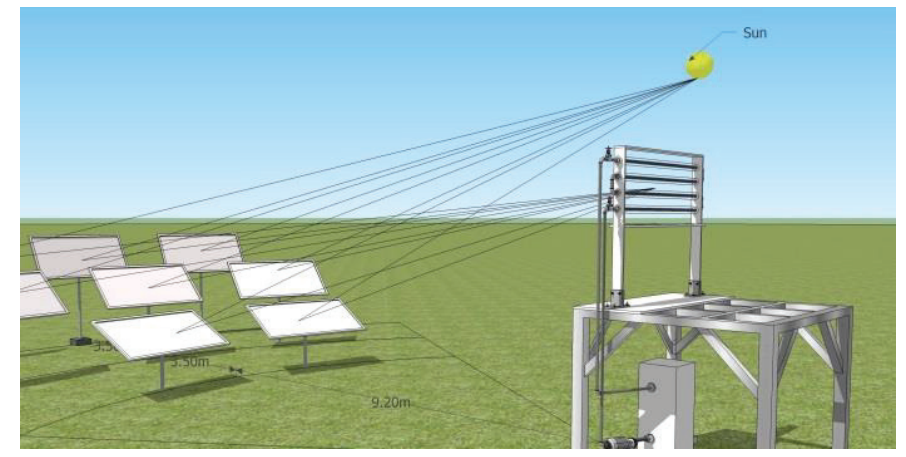

Fig. 1. Schematic diagram of proposed model.

\section{The incident energy}

The field efficiency is the factor that determines the energy of solar radiation that hits the receiver of the tower. This incident energy $\left(\dot{q}_{\text {inci }}\right)$ on the receiver is defined as follows [5].

$$
\begin{gathered}
\dot{q}_{\text {inci }}=Q_{\text {solar }} \times \eta_{\text {field }} \\
\dot{q}_{\text {inci }}=D N I \times A_{H} \times N_{H} \times \eta_{\text {cos }} \cdot \eta_{\text {sha }} \cdot \eta_{\text {blo }} \cdot \eta_{\text {att }} \cdot \rho_{\text {ref }}
\end{gathered}
$$

where $D N I$ represents Direct Normal Irradiance, $A_{H}$ the area of one heliostat, $N_{H}$ the number of all heliostats in a field while $\eta_{c o s}, \eta_{\text {sha }}, \eta_{b l o}, \eta_{a t t}$ and $\rho_{\text {ref }}$ are the cosine, shadowing, blocking, atmospheric attenuation and mirror reflectance losses, respectively.

\section{Mathematical modeling for proposed model}

Basic energy balance equations for the glass cover, the absorber pipe and the fluid are solved using an iterative procedure. To model the collector a number of simplifying assumptions are made. The assumptions are as follows: The collector is in steady state, thermal and radiation properties of the collector materials are independent of temperature and effects of incidence angle on the absorbed solar radiation are not considered. 
Fig. 2 shows the one-dimensional steady-state energy balance for a cross-section of an HCE, with the glass envelope intact.

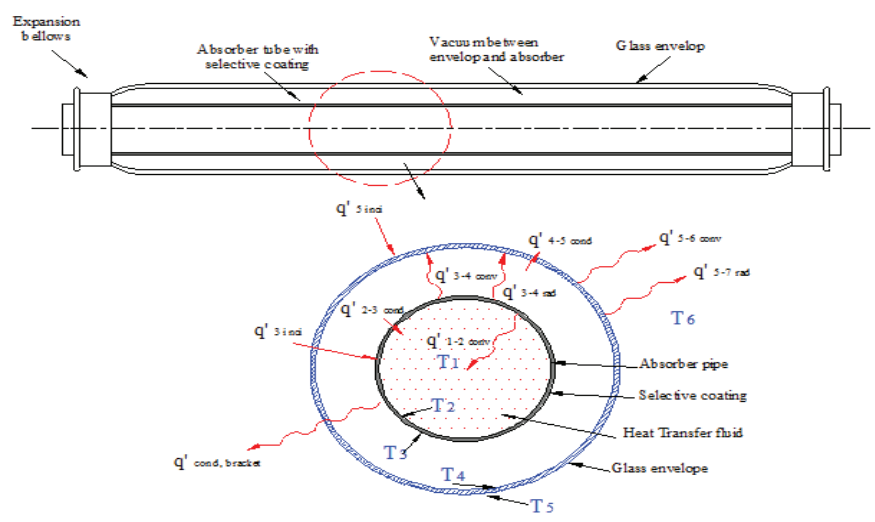

Fig. 2. One-dimensional steady-state energy balance

\section{4-1 Energy Balance Equations between Glass Envelope and Atmosphere}

The energy balance equations between the glass envelope and the atmosphere are represented by following equations presented in this sub-section.

$$
\begin{gathered}
\dot{q}_{4-5, \text { cond }}+\dot{q}_{\text {inci }}=\dot{q}_{5-6, \text { conv }}+\dot{q}_{5-7, \text { rad }} \\
2 \pi k_{4-5}\left(\mathrm{~T}_{4}-\mathrm{T}_{5}\right) / \ln \left(D_{5} / D_{4}\right)+\dot{q}_{s, \text { inci }} \alpha_{e n v}=\overline{N u}_{D 5} \pi k_{5-6}\left(\mathrm{~T}_{5}-\mathrm{T}_{6}\right)+\sigma \mathrm{D}_{5} \pi \varepsilon_{5}\left(\mathrm{~T}_{5}^{4}-\mathrm{T}_{7}^{4}\right)
\end{gathered}
$$

where $\mathrm{k}_{4-5}(\mathrm{~W} / \mathrm{m} . \mathrm{K})$ represents the glass envelope thermal conductance at the average glass envelope temperature given by $\left\{\left(\mathrm{T}_{2}+\mathrm{T}_{3}\right) / 2\right\}$. The subscripts $\mathrm{D}_{5}$ and $\mathrm{D}_{4}(\mathrm{~m})$ refer to the glass envelope's outlet and inlet respectively. ' $q_{s, i n c i}$ is the solar irradiation per receiver length $(\mathrm{W} / \mathrm{m})$ and $\alpha_{e n v}$ is the absorptance of the glass envelope (Pyrex glass), $\mathrm{T}_{5}$ and $\mathrm{T}_{6}\left({ }^{\circ} \mathrm{C}\right)$, represent the glass envelope outer surface temperature and the ambient temperature, respectively, $\mathrm{k}_{5-6}(\mathrm{~W} / \mathrm{m} . \mathrm{K})$ is the thermal conductance of air at temperature $\left\{\left(\mathrm{T}_{5}+\mathrm{T}_{6}\right) / 2\right\}$, $\overline{N u}_{D 5}$ is the average Nusselt number based on the glass envelope outer diameter. $\varepsilon_{5}$ and $\sigma$ respectively represents the glass envelope outer surface emissivity and Stefan Boltzmann's constant $(5.670 \mathrm{E}-8)\left(\mathrm{W} / \mathrm{m}^{2} . \mathrm{K}^{4}\right)$ while $\mathrm{T}_{7}$ is effective sky temperature $(\mathrm{K})$

$\overline{N u}_{D 5}=C \operatorname{Re}_{D, \max }^{m} \operatorname{Pr}_{6}^{0.36}\left(\frac{P r_{6}}{P r_{5}}\right)^{1 / 4}$

This correlation is valid for $0.7 \leq \operatorname{Pr}_{6} \leq 500$ and $1 \leq R e_{D, \max } \leq 10^{6}$. All fluid properties are evaluated at the atmospheric temperature, $\mathrm{T}_{6}$, except $\mathrm{Pr}_{5}$, which is evaluated at the glass envelope outer surface temperature [6]. 


\section{4-2 Energy Balance Equations between Absorber and Glass Envelope}

This subsection contains the energy balance equations between the absorber and glass envelope.

$$
\begin{gathered}
\dot{q}_{3-4, \text { conv }}+\dot{q}_{3-4, \text { rad }}=\dot{q}_{4-5, \text { cond }} \\
\pi \mathrm{D}_{3} \mathrm{~h}_{3-4}\left(\mathrm{~T}_{3}-\mathrm{T}_{4}\right)+\frac{\sigma \pi \mathrm{D}_{3}\left(\mathrm{~T}_{3}^{4}-\mathrm{T}_{4}^{4}\right)}{\left(1 / \varepsilon_{3}+\left(1-\varepsilon_{4}\right) \mathrm{D}_{3} /\left(\varepsilon_{4} \mathrm{D}_{4}\right)\right)}=2 \pi k_{4-5}\left(\mathrm{~T}_{4}-\mathrm{T}_{5}\right) / \ln \left(D_{5} / D_{4}\right)
\end{gathered}
$$

where $\mathrm{D}_{3}$ is outer absorber surface diameter $(\mathrm{m}), \mathrm{T}_{3}$ is outer absorber surface temperature $\left({ }^{\circ} \mathrm{C}\right)$, and $\mathrm{h}_{3-4}$ is convection heat transfer coefficient for the annulus gas at $\mathrm{T}_{3^{-} 4}\left(\mathrm{~W} / \mathrm{m}^{2}-\mathrm{K}\right)$, when the heat transfer is very small pressures $(\sim<0.0001$ torr $)$, the convection heat transfer coefficients $\left(\mathrm{h}_{3-4}\right)$ equals $0.000111 \mathrm{~W} / \mathrm{m}^{2}-\mathrm{K}[7]$.

\section{4-3 Energy Balance Equations for Absorber}

The energy balance equations for the absorber are:

$$
\begin{gathered}
\dot{q}_{\text {inci }}=\dot{q}_{3-4, \text { conv }}+\dot{q}_{3-4, \text { rad }}+\dot{q}_{2-3, \text { cond }} \\
\dot{q}_{s, \text { inci }} \cdot \tau_{\text {env }} \cdot \alpha_{a b s}=\pi D_{3} \cdot h_{3-4}\left(T_{3}-T_{4}\right)+\frac{\sigma \cdot \pi \cdot D_{3}\left(T_{3}^{4}-T_{4}^{4}\right)}{\frac{1}{\varepsilon_{3}}+\frac{\left(1-\varepsilon_{4}\right) D_{3}}{\left(\epsilon_{4} \cdot D_{4}\right)}}+\frac{2 \pi k_{2-3}\left(T_{2}-T_{3}\right)}{\ln \left(\frac{D_{3}}{D_{2}}\right)}
\end{gathered}
$$

where $\alpha_{\text {abs }}$ is the absorptance of the absorber and $\tau_{-}$env is the transmittance of the glass envelope.

\section{4-4 Energy balance equations between the HTF and the Absorber}

For the Heat transfer fluid and the absorber, the energy balance equations are given as:

$$
\begin{gathered}
\dot{q}_{2-1, \text { conv }}=\dot{q}_{2-3, \text { cond }} \\
\mathrm{Nu}_{\mathrm{D} 2} \pi k_{1}\left(\mathrm{~T}_{2}-\mathrm{T}_{1}\right)=2 \pi k_{2-3}\left(\mathrm{~T}_{2}-\mathrm{T}_{3}\right) / \ln \left(D_{3} / D_{2}\right)
\end{gathered}
$$

where $\mathrm{Nu}_{\mathrm{D} 2}$ is the Nusselt number based on $\mathrm{D}_{2}$ and $\mathrm{k}_{1}$ is the thermal conductance of the $\mathrm{HTF}$ at temperature $\mathrm{T}_{1}(\mathrm{~W} / \mathrm{m}-\mathrm{K})$, such that:

$$
\mathrm{T}_{1}=\mathrm{T}_{2}-\left[\frac{2 \pi k_{2-3}\left(\mathrm{~T}_{2}-\mathrm{T}_{3}\right) / \ln \left(D_{3} / D_{2}\right)}{\mathrm{Nu}_{\mathrm{D} 2} \pi k_{1}}\right]
$$

where $\mathrm{D}_{2}$ is the inside diameter of the absorber pipe (m), $\mathrm{T}_{1}$ is the mean (bulk) temperature of the HTF $\left({ }^{\circ} \mathrm{C}\right), \mathrm{T}_{2}$ is the inside surface temperature of absorber pipe $\left({ }^{\circ} \mathrm{C}\right), \mathrm{Nu}_{\mathrm{D} 2}$ is the Nusselt number based on $\mathrm{D}_{2}$ and $\mathrm{k}_{1}$ is the thermal conductance of the HTF at $\mathrm{T}_{1}(\mathrm{~W} / \mathrm{m}-\mathrm{K})$

$$
\mathrm{T}_{o}=2 \mathrm{~T}_{1}-\mathrm{T}_{i}
$$

where $T_{o}$ is the external heat transfer fluid temperature and $T_{i}$ is the internal heat transfer fluid temperature.

$$
\begin{gathered}
\dot{q}_{\text {loss }}=\dot{q}_{5-6, \text { conv }}+\dot{q}_{5-7, \mathrm{rad}} \\
\dot{q}_{\text {useful }}=\dot{q}_{\text {inci }}+\dot{q}_{\text {loss }}
\end{gathered}
$$




$$
\dot{m}=\frac{\dot{q}_{u s e f u l}}{c p\left(T_{o}-T_{i}\right)}
$$

where $\dot{q}_{\text {loss }}$ and $\dot{q}_{\text {useful }}$ are heat loss per unit receiver length $(\mathrm{W} / \mathrm{m})$ and HTF heat gain per unit receiver length $(\mathrm{W} / \mathrm{m}), \dot{m}$ is the mass flow rate of $\mathrm{HTF}(\mathrm{Kg} / \mathrm{s})$ and specific heat of HTF (J/kg.K).

The thermal efficiency can thus be calculated utilizing the following equation;

$$
\eta_{\text {thermal }}=\frac{\dot{q}_{\text {useful }}}{\dot{q}_{\text {inci }}}
$$

Receiver losses can be defined as the product of each efficiency in the loss mode.

$$
\eta_{\text {receiver }}=\eta_{\text {rad }} \cdot \eta_{\text {conv }} \cdot \eta_{\text {spil }} \cdot \eta_{\text {absorp }}
$$

where $\eta_{\text {rad }} \cdot \eta_{\text {conv }} \cdot \eta_{\text {spil }}$ and $\eta_{\text {absorp }}$ are the efficiencies based on the receiver, radiation, convection, and spillage, absorption losses, respectively.

The above equations were used in MATLAB, and a boundary analysis was performed on the system (shown in Figure 1). For the evacuated tube receiver, the input variables needed for calculation are shown in Table 1.

Table 1. Specifications of solar collector

\begin{tabular}{|l|l|}
\hline Model & High temperature solar collector pipe \\
\hline Type & JJR-T-2140 collector tube \\
\hline Length & $2136 \mathrm{~mm}$ \\
\hline Working temperature(Highest) & $>200^{\circ} \mathrm{C}\left(350^{\circ} \mathrm{C}\right)$ \\
\hline Diameter of absorption tube & $40 \mathrm{~mm}$ \\
\hline Diameter of glass tube & $100 \mathrm{~mm}$ \\
\hline Absorptivity & $\geq 0.95$ \\
\hline Emittance & $\leq 0.10 \mathrm{at}$ temperature $200^{\circ} \mathrm{C}$ \\
\hline Transmittance of glass & $\geq 0.91 .5$ \\
\hline Vacuum degree & $3.0 \times 10-4 \mathrm{~Pa}$ \\
\hline
\end{tabular}

\section{Result and discussion}

The data uses direct solar radiation measurements to determine the radiation intensity of the facility located in UTP, Perak. More specifically, the amount of direct-use radiation available from the sun for any given hour of the year. Fig. 3 shows the average daily radiant values of the peak of each month, showing the highest solar radiation reached in February at 12:00. The calculations were carried out in February, where the sun was more visible than other months.

The optical losses in the heliostat field are shown in the bar chart in Fig. 4. The types of optical losses were cosine, shading and blocking, atmospheric attenuation, and mirror reflectance losses. All of those losses were depended on the heliostat field planning and the Sun's Position at any time of day. 


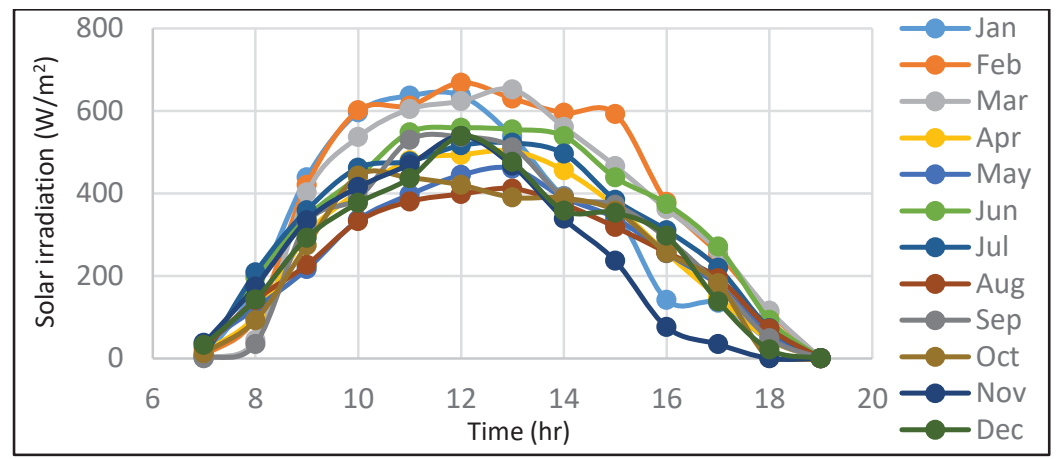

Fig. 3. Portrays an average of hourly values for peak daily radiation of each month.

The energy incident on the receiver depends on the heliostat efficiency directing the solar flux of the sun on the receiver. Fig. 4 shows the optical loss at $12 \mathrm{pm}$ where it is observed that the biggest effect were the losses of the cosine.

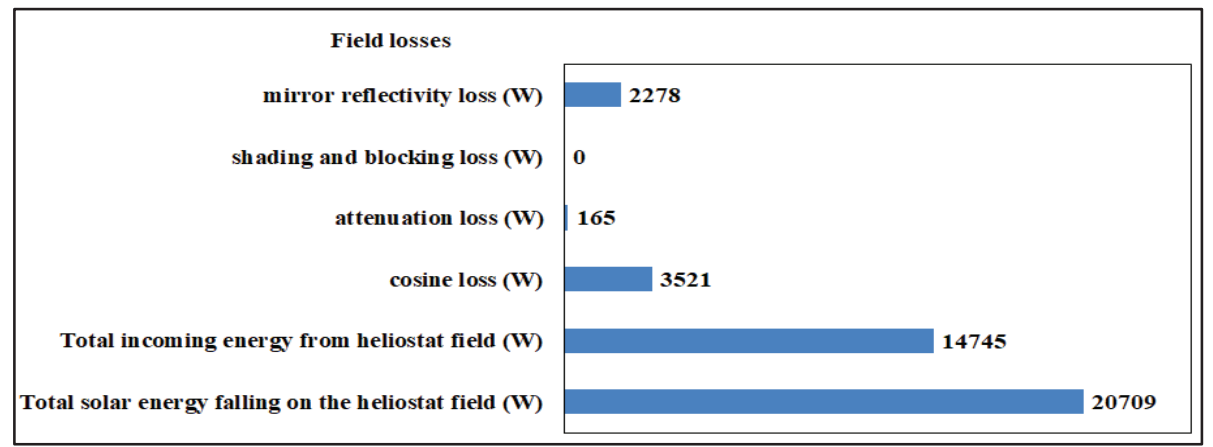

Fig. 4. Breakdown of the energy loss in heliostat field

A parametric analysis was performed to simulate the performance of the evacuated tube and change the above variables. Solar radiation in Perak, Malaysia varies throughout the day. This change is important because it allows us to study the impact of solar intensity on the energy input of the receiver. Fig. 5 shows this relationship. The energy input increases with increased solar irradiation with the increase ranging from 288 to $470 \mathrm{~W} / \mathrm{m}$ at $8 \mathrm{am}$ and $12 \mathrm{pm}$. This implies that the maximum amount of energy inputs that can be obtained in the receiver for a collector is around $470 \mathrm{~W} / \mathrm{m}$ at $12 \mathrm{pm}$ for the maximum solar density of $688 \mathrm{~W} / \mathrm{m}^{2}$. The solar irradiation is $402 \mathrm{~W} / \mathrm{m}^{2}$ at $8 \mathrm{am}$, and the useful energy of collectors is about $288 \mathrm{~W} / \mathrm{m}$. These results show that the receiver will receive more energy at times of high solar intensity, thus increasing the useful energy. Increasing the flux of solar energy doesn't increase the efficiency much, as shown in Fig. 5, the efficiency increase is only from $22.7 \%$ to $23.8 \%$, a total of $1.1 \%$. This is reasonable since low solar flux also reduces the useful energy rate of the receiver and with the knowledge that the flux is also low, the efficiency will remain the same [8]. The efficiency of the receiver is low because spill losses are about 75 percent due to the small receiver space compared to the reflected image area of the heliostat field.

Increasing the flux of solar radiation leads to higher temperatures of heat transfer fluid in the receiver outlet from 92.8 to $151{ }^{\circ} \mathrm{C}$ with increasing mass flow rate from 0.0075 to $0.0122 \mathrm{Kg} / \mathrm{s}$ at $8 \mathrm{am}$ and $12 \mathrm{pm}$, as illustrated in Fig. 6. These results show that the receiver will capture more energy in high solar intensity times. The mass flow rate of this HTF is decisive in the performance of the collector and will result in an increase in the 
useful energy of the receiver. This increase leads to an increase in the temperature of the HTF outlet in the receiver since more energy is captured and delivered to the HTF.

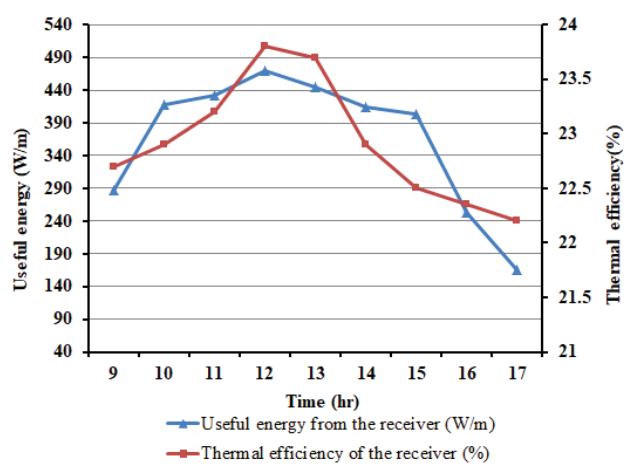

Fig.5. Effect of solar irradiation on the thermal efficiency and useful energy from the receiver.

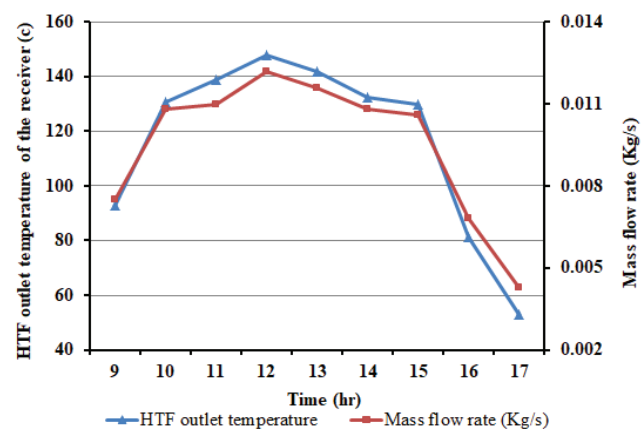

Fig.6. Effect of the solar irradiation on the mass flow rate of HTF and HTF outlet temperature from the receiver.

\section{Conclusions}

The novel concentration of evacuated solar tube receiver system has been developed to produce high temperature. In this paper, the proposed design details and field performance results are presented. The result showed the following:

- To reduce the loss of spill from the receiver, the number of tubes must be increased to intercept the maximum amount of solar energy.

- The biggest losses effect on the optical efficiency is the cosine and spillage.

- The thermal efficiency of the receiver was about $23 \%$.

To increase the output temperature of the receiver as long as the receiver absorbs more heat, so the number of tubes must be increased.

The authors gratefully acknowledge the assistance provided by Universiti Teknologi PETRONAS for the financial and technical support to conduct this research work.

\section{References}

1. O. Garbrecht, F. Al-Sibai, R. Kneer, K. Wieghardt., Journal of Solar Energy Vol 90, 94-106.2013.

2. X. Li, W. Kong, Z. Wang, C. Chang, F. Bai., Renewable Energy Vol 35, 981988.2010.

3. Lata, J.M., Rodrı'guez, M., A ' lvares de Lara, M., Journal of Solar Energy Engineering 130, 021002 (5 pages).2008.

4. X. Yang, X. Yang, J. Ding, Y. Shao, H. Fan., Applied Energy Vol 90, 142-147.2012.

5. R. Pitz-Paal Lecture notes "Solartechnik", RWTH Aachen, 2008

6. R. Forristall., Report No. NREL/TP- 550-34169. CO, USA: NREL.2003.

7. Marshal, N., transl., New York, NY: Elsevier.1976.

8. M. S. Shahin, M. F. Orhan, F. Uygul., Solar Energy Vol 136, 183-196.2016 